\title{
The Kinetics of DNA Uptake by Haemophilus influenzae
}

\author{
BY J. H. STUY AND DORIS STERN \\ Institute of Molecular Biophysics and Department of Biological \\ Sciences, Florida State University, Tallahassee, Florida
}

(Received 11 November 1963)

\begin{abstract}
SUMMARY
The rates of formation of transformed cells in mixtures of transforming DNA and transformable Haemophilus influenzae bacteria have been measured. The data were interpreted as follows. About 4-5 sec. are required for the penetration of a DNA particle of $8-9 \times 10^{6}$ mean molecular weight. The average number of penetration sites per bacterium is probably two. There is no reversible attachment of DNA to these sites. Crude calculations show that about one out of every two encounters between a bacterium and a DNA molecule results in the penetration of the latter into the cell.
\end{abstract}

\section{INTRODUCTION}

Haemophilus influenzae is one of the few bacterial species showing DNA-mediated alteration of genotype (bacterial transformation; Alexander \& Leidy, 1951). The first step in this process is believed to be a reversible adsorption (attachment) of the DNA to the cells (Fox \& Hotchkiss, 1957; Lerman \& Tolmach, 1957; Goodgal \& Herriott, $1961 a$ ). Reversible attachment is followed by irreversible absorption (uptake) of the DNA; i.e. the latter has become non-susceptible to DNase and can actually be re-isolated by opening the recipient bacteria. Eventually, the penetrated DNA is in some unknown way incorporated into the bacterial genome.

The ability to take up DNA is not a normal property of Haemophilus influenzae. The bacteria have to be grown in a special way in order to render them highly transformable (competent; Stuy, 1960; Leidy, Jaffee \& Alexander, 1962; see also Goodgal \& Herriott, $1961 a$, for a somewhat contradictory report). Recent experiments suggested that transformable bacteria possess an enzyme system which actively participates in the uptake of DNA, i.e. in the irreversible step (Stuy, 1962).

We felt that kinetic measurements of the DNA uptake by transformable bacteria would give us an insight into the nature of the penetration process. The velocity and the order of the uptake phenomenon, the saturation of this process by high DNA concentrations and the lag period in the appearance of transformants might tell us, for instance, (1) whether there is significant reversible attachment of DNA to the penetration sites, (2) the time required for the penetration of one DNA molecule, (3) the number of penetration sites per bacterium, and (4) the nature of those sites. A report on these data will be given and their significance discussed. 


\section{EXPERIMENTAL}

All transformation techniques have been fully described elsewhere (Stuy, 1959, 1960). The bacterial strain studied was Haemophilus influenzae Rd. Sedimentation constants of the DNA preparations employed were determined at $20 \mu \mathrm{g} . / \mathrm{ml}$. in standard saline + citrate solution $(0 \cdot 15 \mathrm{M}-0 \cdot 015 \mathrm{M})$. Molecular weights (particle size) were derived from these constants according to Doty, McGill \& Rice (1958). All DNA solutions added to bacteria were $0.15 \mathrm{M}$ with respect to $\mathrm{NaCl}$.

The experiments were run as follows: $0.2 \mathrm{ml}$. of transformable bacteria in $0 \cdot 15 \mathrm{M}$ saline $+10 \%$ Levinthal broth was pipetted into a hole (radius, $5 \mathrm{~mm}$.; depth, $10 \mathrm{~mm}$.) in a Perspex disc. The suspension was stirred vigorously at about four rev./sec. using a magnetic stirrer and a $6 \mathrm{~mm}$. piece of paperclip. At time zero, $0 \cdot 1 \mathrm{ml}$. of a DNA solution was 'shot in' by means of a wide-bore syringe (without needle). The reaction was terminated by 'shooting in' $0.1 \mathrm{ml}$. of DNase (Worthington Laboratories; final concentration, about $90 \mu \mathrm{g} . / \mathrm{ml}$. in $\left.0.003 \mathrm{M}-\mathrm{MgSO}_{4}\right)$. It was assumed that the DNase would remove (and destroy) any DNA adsorbed to the bacteria. Transformants were scored from appropriate dilutions using the agar double-layer technique: the bacteria were plated in $5 \mathrm{ml}$. of Levinthal agar, incubated for $2 \mathrm{hr}$ at $37^{\circ}$. The plates were then overlayered with $10 \mathrm{ml}$. of antibiotic-containing agar. Only cells transformed to antibiotic resistance were able to form visible colonies during overnight incubation.

When DNA was added to the suspension after the DNase, even within a second, transformants were never formed. This indicates that the enzyme stopped the DNA uptake in less than a second.

'Unstirred' exposure to DNA was accomplished by stirring the suspension only for 3 sec. on the addition of the DNA and the DNase.

Competence (transformability) of the bacteria was in every experiment determined before and after the kinetic measurements by exposing separate aliquots to excess DNA for $10 \mathrm{~min}$. It did not change significantly.

The bacterial concentration, after addition of DNA, did not differ in any experiment more than $20 \%$ from $1.5 \times 10^{8}$ viable centres $/ \mathrm{ml}$. unless otherwise stated.

The streptomycin resistance (SM) marker conferred upon the bacteria resistance to $2 \mathrm{mg}$. $/ \mathrm{ml}$. of the antibiotic, while the cathomycin (novobiocin) resistance (Ca) marker increased their resistance to about $5 \mu \mathrm{g} . / \mathrm{ml}$. These markers are linked; i.e. they are located on the same DNA particle. In crosses of strain Rd with DNA carrying both markers, transformation to resistance against both antibiotics is observed in about one-third of all transformations.

\section{RESULTS}

General. Figures 1 and 2 show the formation of transformants in stirred and unstirred mixtures of transformable bacteria and excess DNA (Fig. 1) and limiting amounts of DNA (Fig. 2). DNA activity was determined as $1.5 \times 10^{8}$ transformations to cathomycin resistance per $\mu \mathrm{g}$. (in previous standard activity tests) and its molecular weight at $9 \times 10^{6}\left(\mathrm{~S}_{20}, \mathbf{2 5 \cdot 3}\right)$. Assuming that all DNA particles were taken up equally well, the specific activity is then one transformation for every 450 molecules absorbed (derived from use of Avogadro's number).

As can be seen, the curve in Fig. 1 extrapolates to a value of about 3 sec. Trans- 
formants were observed, however, after exposure times as short as $\frac{1}{2}$ sec. The uptake seemed to proceed semi-logarithmically with exposure time up to 4 sec. but it is pointed out that these numbers of transformants showed rather large fluctuations from experiment to experiment, which is probably due to inaccurate timing. The extrapolated value of about 3 sec. which we call lag period was further investigated.

Stirring the mixtures increased the uptake rate only when low DNA concentrations were employed. This indicates that it effected enhanced contact between bacterium and DNA.

Kinetic measurements. The uptake of DNA by bacteria can theoretically be described by either of two mechanisms.

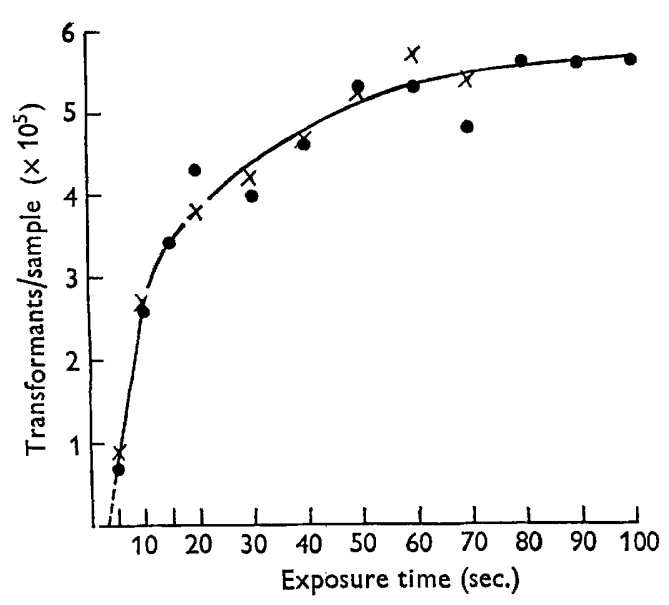

Fig. 1

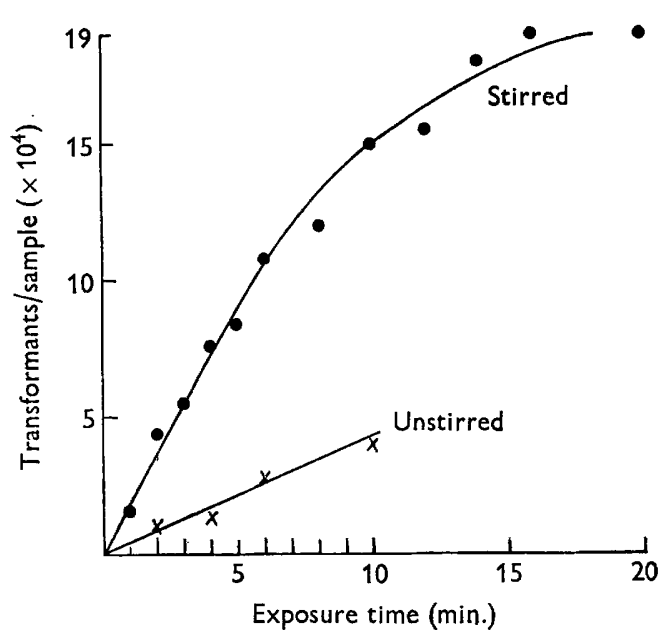

Fig. 2

Fig. 1. Formation of transformants for cathomycin resistance in stirred mixtures of transformable bacteria $\left(5 \times 10^{7} / 0 \cdot 3 \mathrm{ml}\right.$.) and DNA $(1.7 \mu \mathrm{g} . / 0 \cdot 3 \mathrm{ml}$.). Dots and crosses represent two independent experiments. Competence was determined as $2.4 \times 10^{-2}$.

Fig. 2. Formation of transformants for cathomycin resistance in stirred and unstirred mixtures of transformable bacteria and DNA $(0 \cdot 0017 \mu \mathrm{g} . / 0 \cdot 3 \mathrm{ml}$.). Total activity added, $2.5 \times 10^{5}$ transformations per sample.

(a) Bacteria $+\mathrm{DNA} \rightleftharpoons$ complexes $\rightarrow \rightarrow$ transformants, in which the first step, the reversible attachment of the DNA to the penetration sites, is followed by one or more penetration steps; or

(b) bacteria + DNA $\rightarrow \rightarrow$ transformants, in which there is no reversible attachment of DNA to the penetration sites.

In case $(a)$ we might interpret the lag period as the time necessary for the reversible attachment to reach equilibrium. Hereafter, DNA penetration will proceed linearly with time at a rate proportional to the concentration of the cell-DNA complexes. At first sight, the lag period must vary with DNA concentration.

In case $(b)$ we might interpret the lag period as the average penetration time for the DNA particle. If strict linear penetration takes place the lag period of 3 sec. would mean a total absorption time of some 6 sec. for the entire DNA particle if it be assumed that the genetic marker is on average midway situated on the molecule. 
Such a model implies that the part of the particle outside the bacterium is still susceptible to DNase. The lag period must be independent of the DNA concentration.

These models are simple and the actual penetration mechanism is probably much more complex. Of course, we may also have a situation composed of both possibilities.

To test both models, DNA uptake was measured in mixtures of bacteria and varying amounts of DNA under conditions giving linear formation of transformants with time. This was realized by stopping the measurements before $20 \%$ of the DNA or the bacteria had participated in the reaction. From the kinetic point of view both bacterial and DNA concentration can be considered to have remained constant during the reaction. The DNA employed had an $S_{20}$ value of $30 \cdot 0$, which

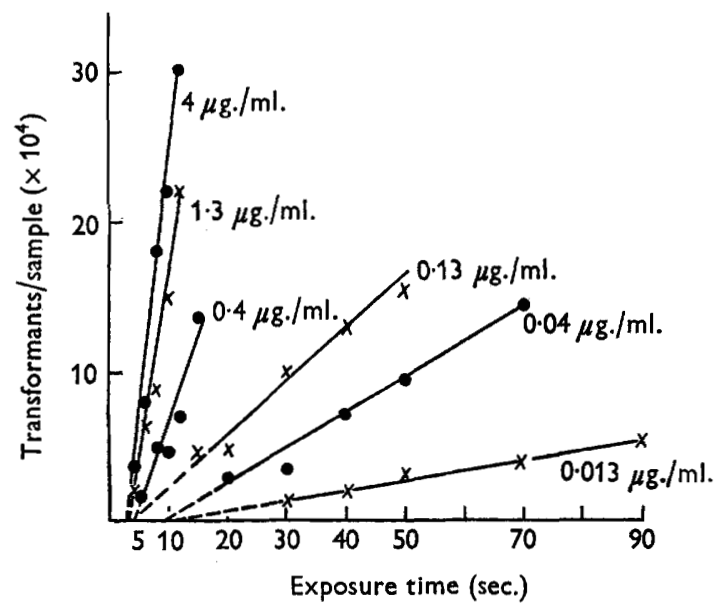

Fig. 3

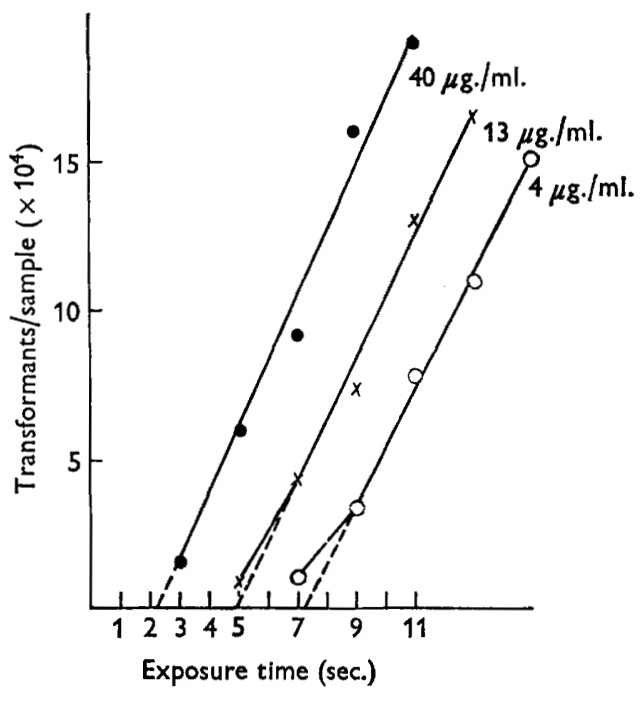

Fig. 4

Fig. 3. Formation of transformants for streptomycin resistance in stirred mixtures of bacteria and DNA at indicated concentrations. Particle size of DNA: $14 \times 10^{6}$,

Fig. 4. Formation of transformants for streptomycin resistance in stirred mixtures of bacteria and DNA at indicated concentrations. Particle size of DNA: $14 \times 10^{6}$. Middle curve is shifted 2 sec. and right curve 4 sec. to the right for the sake of clarity.

corresponds to a mean particle size of $14 \times 10^{6}$. Its activity, as measured in standard activity tests, was 1.5 $\times 10^{8}$ transformations per $\mu \mathrm{g}$. By using Avogadro's number, this relates to one transformation per 300 molecules.

As can be seen in Figs. 3 and 4, there was not more than a sixfold fluctuation in the lag period over a range in DNA concentration of 3000. Experiments with other DNA preparations gave similar results. When excess DNA was employed, a lag period of about 2.5 sec. was invariably observed (Fig. 4).

The linear relationship between rate of uptake and DNA concentration was observed up to about $1.3 \mu \mathrm{g} . / \mathrm{ml}$., above which there was little further increase (Fig. 5). All data obtained are represented; the small differences in the rates observed in separate experiments were corrected for by means of reference curves. Saturation of the bacteria takes place when there are about 300 DNA particles per bacterium. 
Exposure to $D N A$ in the cold. Competent bacteria transform very poorly if exposed to DNA at low temperatures. The penetration step being an enzymic reaction is likely to be temperature dependent while mere attachment is probably not influenced by temperature decrease if it is due to electrical attraction.

On the basis of these assumptions it seemed possible to obtain data about the significance of the latter process by measuring that fraction of the DNA, attached in the cold to the bacteria, that would be taken up upon instantaneous raising of the temperature. About $2 \times 10^{8}$ pre-chilled bacteria per ml. were incubated at $0^{\circ}$ with $0 \cdot 4 \mu \mathrm{g}$. DNA $/ \mathrm{ml}$. (ratio of 85 particles to one bacterium) for $2 \mathrm{~min}$. It can be roughly calculated that in that period every bacterium had an average of $15 \mathrm{en}$ -

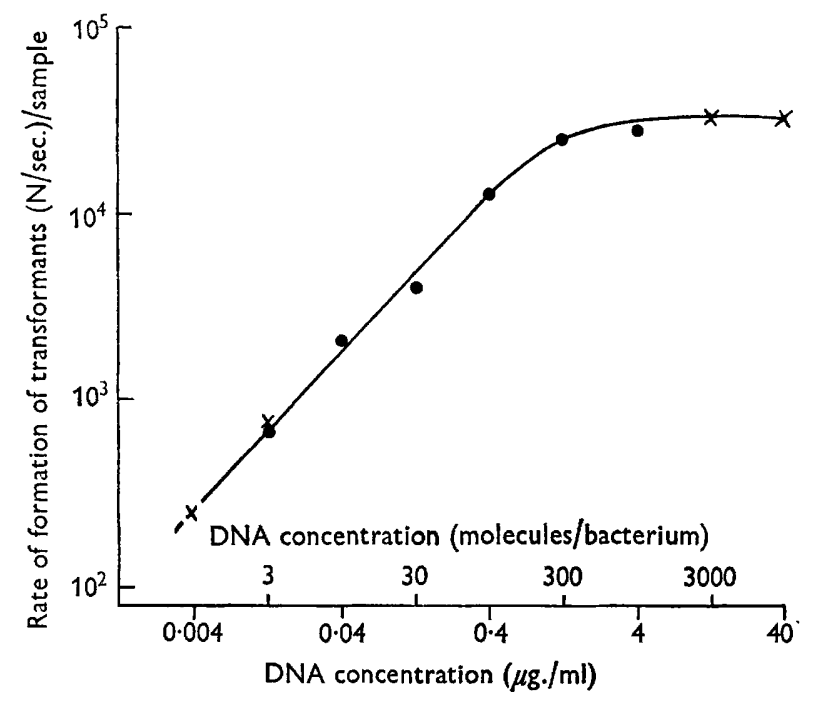

Fig. 5. Relationship between rate of formation of transformants and concentration of DNA. Particle size: $14 \times 10^{6}$.

counters with a DNA particle (see Discussion about encounter efficiency). The mixture was thereafter diluted 100 -fold with a chilled pipette into (1) warm $\left(37^{\circ}\right)$ broth containing $10 \mu \mathrm{g}$. DNase $/ \mathrm{ml}$. and $0.003 \mathrm{M}-\mathrm{MgSO}_{4}$ in order to find the number of bacteria which had taken up a genetically marked DNA particle in the cold, and (2) warm broth containing $\mathrm{MgSO}_{4}$ while DNase was added 10 sec. later, to give any attached DNA a chance of being absorbed. To determine the background number of transformants formed in the broth due to fresh encounters between bacteria and DNA before addition of the DNase, transformable non-exposed bacteria were diluted as under (2) in broth containing 0.004 $\mu \mathrm{g}$. DNA $/ \mathrm{ml}$. and DNase was added after 10 sec. Transformants were scored as usual. In a typical experiment, the last (diluted) suspension contained 65 transformed bacteria per ml.; suspension (1) 80 and suspension (2) 340. Against a total background of 145 transformants we observed that only 195 out of $2 \times 10^{6}$ bacteria were transformed as a consequence of the 'complexing with DNA'. Taking into account that, for every transformant scored, 300 DNA molecules had been taken up (i.e. the specific activity of the DNA used), we calculate that about $6 \times 10^{4}$ molecules had penetrated into the $2 \times 10^{8}$ 
bacteria per ml., that is in about $3 \%$ of all possible cases. We believe that these data argue against reversible attachment of DNA to the penetration sites on transformable bacteria. In suspension (2) we have observed all bacteria which were in the process of absorbing a marked DNA molecule while in suspension (1) we counted those bacteria having the genetic marker 'inside' already.

Effect of 2, 4-dinitrophenol. This compound had been found to block reversibly the uptake of DNA (Stuy, 1962), which suggested to us the participation of an enzyme system in the irreversible step. We were for this reason interested in a more detailed study of the inhibition.

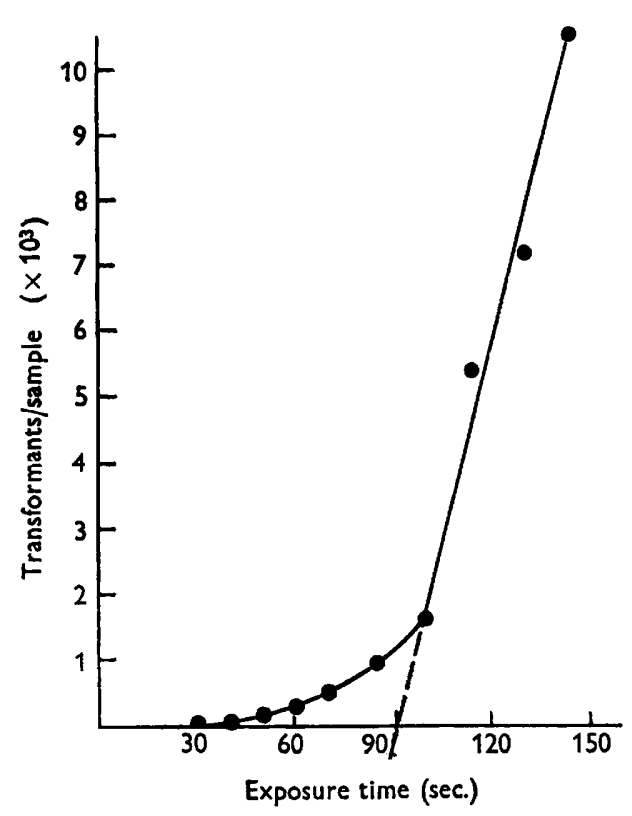

Fig. 6

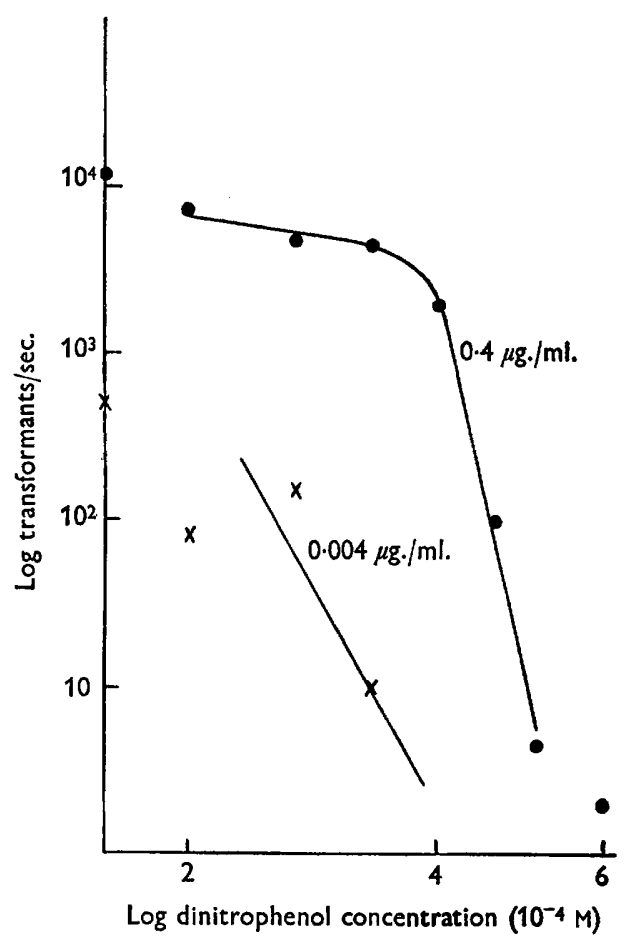

Fig. 7

Fig. 6. Formation of transformants for streptomycin resistance in stirred mixtures of bacteria and DNA $\left(0.4 \mu \mathrm{g} . / \mathrm{ml}\right.$.) in the presence of $4.7 \times 10^{-4} \mathrm{M}-2,4$-dinitrophenol.

Fig. 7. Rate of formation of transformants for streptomycin resistance in stirred mixtures of bacteria and DNA at the indicated concentrations as a function of 2,4-dinitrophenol concentration.

Transformable bacteria were pre-incubated in 2,4-dinitrophenol for 5 min., after which DNA was added. Such pre-incubation had no measurable effect upon cell viability nor on transformability, which was established after having diluted out the dinitrophenol. Figure 6 shows that $4 \cdot 7 \times 10^{-4} \mathrm{M}-2,4$-dinitrophenol increased the lag period from about $3 \mathrm{sec}$. to $80-85 \mathrm{sec}$. while decreasing the rate of DNA uptake from $10^{4}$ to $2 \times 10^{2}$ transformants $/ \mathrm{sec}$. $/$ sample of $0.3 \mathrm{ml}$. These two effects were always observed; however, we could not establish a strict relationship between them. It was also difficult to reproduce accurately a given inhibition from day to day with the 
same dinitrophenol concentration but this is probably explained by the steep action profile (Fig. 7).

The complete reversibility of the dinitrophenol effect, the low inhibitory concentration (which also just inhibited growth in broth) and the steep action profile argue against the view that dinitrophenol might bind to either DNA or penetration sites, in this way exerting its effect. Instead, we believe that dinitrophenol interferes with the flow of energy required for the DNA penetration step. The longer lag period and the decreased rate of DNA uptake indicate strongly that both are parameters for the active uptake process.

Measurement of the time necessary for the penetration of a DNA particle. A lag period of $2.5 \mathrm{sec}$. had been found for the appearance of transformants in mixtures of transformable bacteria and three DNA preparations. Although it appeared this delay was somehow related to the penetration step, it did not necessarily represent the total absorption time for a DNA particle. We thought that we could measure this time directly by exposing bacteria to an excess of DNA specific for one genetic marker for a very short time (in order to occupy all penetration sites), then adding DNA specific for another marker and following the uptake of both DNAs. Our assumption was that the second DNA could not penetrate into the bacteria before the sites had become free again. The lag period in the formation of transformants by the second DNA would then be the time required for the absorption of the first DNA.

To $0.2 \mathrm{ml}$. of transformable bacteria (stirred), $0.1 \mathrm{ml}$. of DNA(Ca) was added. After 2 sec., when each bacterium had had about four encounters with a DNA particle (see Discussion about encounter efficiency), 0.1 ml. of DNA(SM) was 'shot in'. The latter DNA had a particle size of $8 \times 10^{6}$ and a specific activity of $1.3 \times 10^{8}$ transformations per $\mu \mathrm{g}$. The final concentration of both DNAs was about $4 \mu \mathrm{g} . / \mathrm{ml}$. The results (and those of repeated experiments) show that the uptake curve for the first DNA extrapolates to about 2.5 sec. while the uptake curve for the second DNA extrapolates to about 6.5 sec. (Fig. 8). Assuming some linear model for the DNA penetration, the time necessary for the uptake of a DNA particle is $4 \mathrm{sec}$.

Number of penetration sites per bacterium. We can obtain from Fig. 5 some information about the average number of penetration sites per bacterium. The rate of formation of transformants in saturating DNA solutions was about $3.3 \times 10^{4} / \mathrm{sec}$./ sample of $0.3 \mathrm{ml}$. The specific activity of the DNA used being one transformation per 300 DNA particles, the number of absorptions per second per sample equalled about $10^{7}$. Since every sample contained roughly $5 \times 10^{7}$ transformable bacteria, an average number of one penetration site per bacterium would mean a DNA uptake time of 5 sec., two such sites would mean $10 \mathrm{sec}$., three sites $15 \mathrm{sec}$. and so on. In view of the measured absorption time of 4-5 sec., the average number of sites is most likely one. Because of wide margins in the values used, a number of two, or even three, cannot be excluded. We believed we could decide between the two most likely possibilities by exposing bacteria to a mixture of two different DNAs and scoring for single and double transformants. The appearance of doubles will show a lag period of 6-7 sec. if the bacteria have only one site. For two, or more, sites per cell, an equally long lag period for single and double transformants can be expected.

In order to achieve greater experimental sensitivity, transformable bacteria were concentrated 10-fold. A mixture of DNA(SM) and DNA(Ca) was added at time zero 
and the reaction terminated as usual. The final concentration for each DNA was $2 \mu \mathrm{g} . / \mathrm{ml}$. The results show that the lag period for single transformants (plotted linearly against time) and double transformants (square root of their numbers is plotted because they increase to the second power with time) is between 2 and 3 sec. (Fig. 9). From this, and from above calculation, we conclude that the average number of penetration sites per bacterium is probably two.

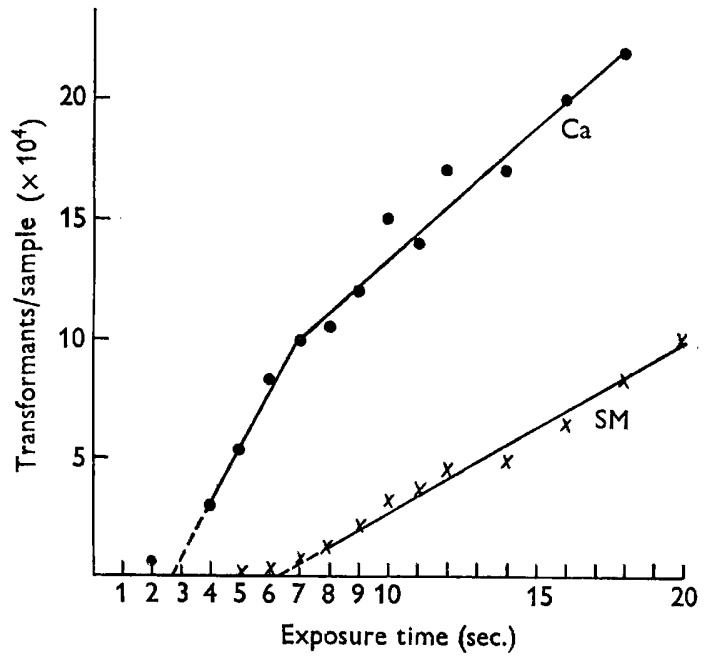

Fig. 8

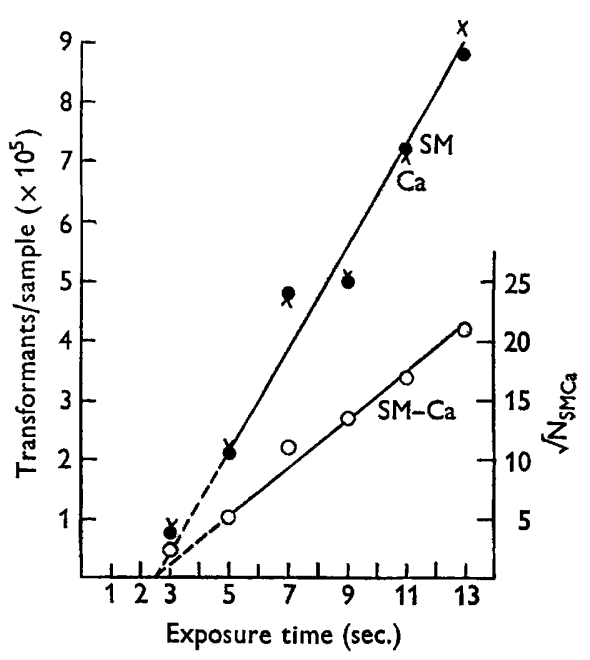

Fig. 9

Fig. 8. Formation of transformants in stirred mixtures of bacteria and two differently marked DNAs. DNA(Ca) was added at time zero (final concentration, $4 \cdot 3 \mu \mathrm{g} . / \mathrm{ml}$.). DNA(SM) was added two seconds later (final concentration, $4 \cdot 0 \mu \mathrm{g} . / \mathrm{ml}$.).

Fig. 9. Formation of single and double transformants in mixtures of bacteria and two differently marked DNAs, added simultaneously. The two DNAs had nearly equal particle sizes and transforming activity.

\section{DISCUSSION}

We have observed a linear increase of transformed bacteria with time in mixtures of Haemophilus influenzae cells and transforming DNA. If we assume that all DNA molecules are equally well taken up, DNA penetration into the bacteria proceeded linearly with time. The uptake curve did not go through the origin but extrapolated to a value of about $2.5 \mathrm{sec}$. when saturating DNA concentrations were used and to somewhat higher values at lower DNA concentrations. The uptake rate was proportional to DNA concentration up to 300 particles per bacterium, above which there was little further increase. The lag period (the extrapolated time) was greatly lengthened by 2, 4-dinitrophenol while the uptake rate was considerably reduced. These facts strengthen our view that an enzyme system (which we have tentatively called DNA permease) participates in the penetration of DNA through the cell membrane.

The data did not provide us with a clear model of DNA uptake. But assuming some linear penetration process (i.e. from end to end) we believe that the lag period of $2.5 \mathrm{sec}$. is closely related to the actual penetration time. The measured lag period of 4-5 sec. in the case of two DNAs, added successively, may be the actual average 
penetration time. Accepting this value, we calculated the most likely average number of penetration sites per bacterium. Experimental evidence indicated at least two sites. At present we favour this number. Whether it should be seen as two discrete sites, or as the cell's inability to handle more than two DNA particles simultaneously, is still unknown.

In spite of the small number of sites we can calculate a high encounter efficiency between bacterium and DNA molecule. The number of encounters per second per $\mathrm{ml} .(F)$ in colloidal systems is, according to Smoluchowski (1917):

$$
F=4 \pi B D\left(D_{B}+D_{D}\right)\left(r_{B}+r_{D}\right),
$$

in which $B$ and $D$ are the respective numbers of bacteria and DNA particles per ml., $D_{B}$ and $D_{D}$ the corresponding diffusion coefficients, $r_{B}$ and $r_{D}$ the corresponding radii. Assuming $D_{B}$ to be small relative to $D_{D}$ and $r_{D}$ to be small relative to $r_{B}$, we write

$$
F=4 \pi B D r_{B} D_{D}
$$

$B$ is $1.7 \times 10^{8}$; for $D$ we take the value of $0 \cdot 4 \mu \mathrm{g} . / \mathrm{ml}$., which is the highest point on the linear part of the curve in Fig. 3, $100 \times 1.7 \times 10^{8} ; r_{B}$ is approximated to $10^{-4} \mathrm{~cm}$. For the value of $D_{D}$ we depended on the validity of the currently asserted molecular weight-sedimentation coefficient relationship which we substituted in the Svedberg equation (Elias, 1962). This gave us $6 \times 1^{-9}$, which is about half the value mentioned for Haemophilus influenzae DNA (Goodgal \& Herriott, 1961b). We arrive then at $2 \cdot 1 \times 10^{7}$ encounters $/ \mathrm{sec} . / \mathrm{ml}$. at $0 \cdot 4 \mu \mathrm{g} . / \mathrm{ml}$. of DNA. The rate of formation of transformants was under these conditions equal to $1 \cdot 1 \times 10^{4} / \mathrm{sec}$. $/$ sample of $0 \cdot 3 \mathrm{ml}$. (Fig. 3). Combining this with the specific activity of the DNA used, i.e. one transformation per 300 molecules absorbed, we find that there were $1 \cdot 1 \times 10^{7}$ absorptions of DNA particles per second per ml. The encounter efficiency, then, is about half.

To understand this high value more readily with respect to the two penetration sites per bacterium, we point at (1) the fact that there can be many collisions between bacterium and DNA particle during an encounter (i.e. the period that they are in each other's close vicinity); (2) the fact that stirring may have altered the shape of the randomly coiled DNA particle, stretching it, so that the chance of contacting a bacterium became enhanced; and (3) the absorption sites may be 'studded' with positive electric charges which attract the DNA strongly through its negatively charged phosphate groups.

The reported data exclude passive DNA uptake as a diffusion process through pores in the cell membrane. The speed and kinetics of the uptake, the strong temperature dependence and the inhibition by dinitrophenol indicate an active transport through the membrane. Although we cannot yet present a model explaining all observations, we believe that our data suggest linear DNA penetration and that they rule out pinocytosis.

This work was done under a contract with the Division of Biology and Medicine, U.S. Atomic Energy Commission and the Florida State University.

One of the authors (J.H.S.) was on leave from the Philips' Research Laboratories, Eindhoven, Netherlands. 


\section{REFERENCES}

Alexander, H. E. \& Leidy, G. (1951). Determination of inherited traits of H. influenzae by desoxyribonucleic acid fractions from type-specific cells. J. exp. Med. 93, 345 .

Doty, P., McGill, B. B. \& Rice, S. A. (1958). The properties of sonic fragments of deoxyribose nucleic acid. Proc. nat. Acad. Sci., Wash. 44, 432.

Elias, H. G. (1962). In Ultrazentrifugen-Methoden, p. 116. München: Beckman Instruments GmbH.

Fox, M. S. \& Hotchkiss, R. D. (1957). Initiation of bacterial transformation. Nature, Lond. 179, 1322.

Goodgal, S. H. \& Herriott, R. M. (1961 a). Studies on transformation of Haemophilus influenzae I. Competence. J. gen. Physiol. 44, 1201.

Goodgal, S. H. \& Herriotr, R. M. (1961 b). Studies on transformation of Haemophilus influenzae II. The molecular weight of transforming DNA by sedimentation and diffusion measurements. J. gen. Physiol. 44, 1229.

Leidy, G., Jaffee, I. \& Alexander, H. E. (1962). Emergence of competence (for transformation) of three Haemophilus species in a chemically defined environment. Proc. Soc. exp. Biol., N.Y. 111, 725.

Lerman, L. S. \& Tolmach, L. J. (1957). Genetic transformation I. Cellular incorporation of DNA accompanying transformation in Pneumococcus. Biochim. biophys. Acta, 26, 68.

Smoluchowski, M. v. (1917). Versuch einer mathematischen Theorie der Koagulationskinetik kolloider Lösungen. Z. phys. Chem. 92, 129.

Stuy, J. H. (1959). Studies on the mechanism of radiation inactivation of microorganisms V. Deoxyribonucleic acid metabolism in ultra-violet irradiated Haemophilus influenzae. J. Bact. 78, 49.

STUy, J. H. (1960). Studies on the mechanism of radiation inactivation of microorganisms VI. X-ray-induced breakdown of deoxyribonucleic acid in Haemophilus influenzae and in other bacteria. J. Bact. 79, 707.

Stuy, J. H. (1962). Transformability of Haemophilus influenzae. J. gen. Microbiol. 29, 537. 